\title{
VR 360 as an Alternative for Virtual-Based Practicum Learning with Stereoscopic View
}

\author{
Ary Budi Warsito ${ }^{* 1}$, Eliando ${ }^{2}$, Muhamad Yusup ${ }^{3}$ \\ ${ }_{1,2}^{1}$ University Maranata, ${ }^{3}$ University of Raharja \\ Email : ${ }^{* 1}$ arybudiwarsito@matanauniversity.ac.id, ${ }^{2}$ eliando@ matanauniversity.ac.id, \\ ${ }^{3}$ yusup@ raharja.info
}

\begin{abstract}
School education especially on primary school have a big impact to the children. Good and right education can sharpening the brain and influence the student with good attitude. Every information that attractive and easy to understanding is very important to give big impact for every primary school student, it also can provide a pleasant learning experience for these students. Therefore, this research develops a smartphone application that can provide a pleasant experience in learning knowledge of the surrounding environment from objects with virtual reality technology. To display these objects, a $360^{\circ}$ panoramic image is used or a 2048px width 1024px width with a wide viewing angle (360 degrees) and this can be done by teachers to make the image or search for material sources on the internet. This technology allows students to see objects virtually. In use, this study requires a VR headset as a device for visualizing stereoscopic displays but it does not need installation because it is enough to access a smartphone browser then it will work. The system is designed using the spiral method as a process model and uses a-frame in application development. The interface can be run on the Android operating system. In making this application using the html programming language, laravel framework and a-frame framework.
\end{abstract}

Keywords — Virtual Reality, Primary School, Panoramic 360

\section{INTRODUCTION}

Today technology it has developed rapidly and change people perspective about information system on using internet. It became one of the crucial aspect of people nowadays. Text based reading is the most commonly found when people access in the internet. Furthermore, people are difficult to find the information especially for education website that provide audio visual support. Even though there are several education website have interactive game but seems kids are not excited to play. Mostly children or students prefer to do online gaming which is become their addictive habit.

Therefore facilities provision of information in the form of update online media is become a must for school and stakeholders to offer. In order to support the sources of information in interactive approach toward picture (visual media). SMK YADIKA 5 is the place for the writer to conduct for the research. One of the school in Tangerang that has many barrier to support the on line media for students there. Since this covid 19 pandemic students do the on line / streaming school from home, picture for support visual media is necessary. The view that we know is the object of $2 \mathrm{~d}$ has started to be shown in the form $3 \mathrm{~d}$ with the help of computer programming language or commonly called 360 panoramic images.

A collection of images is often called figure panorama or commonly called virtual tour to create a similar to the original place, it applied in the tourism that can be accessed via 
electronic media. The writer arranged this research based on education system attempt the students to imagine the situation as if they have the real classroom.

\section{LITERATURE STUDIES}

Foto Panoramic 3600 mempunyai kelebihan pada momen nyata yang tidak ada pada model foto jenis lain ${ }^{[4]}$. Dengan Foto Panoramic 360o, pengguna dapat melihat sekeliling secara $360 o$ dan pengguna dapat merasakan pengalaman 'pernah berada' di suatu tempat hanya dengan melihat layar smartphone ${ }^{[5][6]}$.

Panoramic $360 \mathrm{o}$ is technique to display the borderless photo (withour border) and seamless (without crop) so we can see whole picture ${ }^{[1]}$. It is different from Photogrammetry, Panoramic 360o does not create 3D object ${ }^{[2]}$. The use of photographs panoramic $360 \mathrm{o} \mathrm{can}$ make a an image visible perspective for a broad namum need device vr headset ${ }^{[3]}$. Vr headsets used to display pictures stereoscopic.By using vr headsets, users can enjoy the look of virtual reality ${ }^{[4]}$. Panoramic $360 o$, the user can see the whole panoramic even feel the real situation only by seeing the smartphone screen ${ }^{[5][6]}$.

The technology panorama 360o this study make innovation by making application smartphone with stereoscopic display allowing tourists in exploring images in 360o. In the beginning of this research, the researcher discusses about research approach. In the second chapter the researcher discusses about conceptual and theory, the last chapter is implementation.

Multimedia can be explained as the use of computers to mix it up, text a graph, audio, Motion pictures by the a link as navigation and interaction with the application. There are five multimedia elements to applied are: 1) The text as a medium of communication for instruction for effective user, 2) Charts can be as an alternative text usually live in icon, 3) Often used is the midi and mp3, 4) Video the media that get closer as the truth. 5) Animation is a process is natural for our understanding of the world, we become familiar with it.

Virtual tour is a simulation of a neighborhood real, displayed online, Usually see consisting of a collection of photographs, a collection of picture connected by hyperlink, video or virtual model of the real location, able to use multimedia aspects such as audio, music, narration and text ${ }^{[1]}$.

Virtual Reality is technology that make the user can interact with the virtual place which is stimulated by computer system. As the result users are able to feel the real situation even it is only virtual stimulation ${ }^{[2][5][4]}$.Virtual Technology is face to face technology between human and machine which able to stimulate users experience the real natural environment such as vision, audio, movement and other action. Not only describe the place in detail, but also Virtual Reality allows users to scan the environment virtual and feels like being on the spot ${ }^{[2]}$.

A-frame is web framework facilitated developer to build virtual reality by experience in web browser. A-frame itself comes from Mozilla Vr initiation to build Web VR become easier and faster in Web VR development technology. A-frame uses tree.js draft.

\section{RESEARCH METHOD}

A. Spiral Model

In order to explain this model researcher uses spiral model technique is adapted from 2 different model device such as prototyping repetition of waterfall by controlling the 
mathematic system ${ }^{[7]}$. By doing this model the researcher is able to do several steps from the beginning until the end of the process. The researcher able to avoid the management risk, enhance the process of software development. Below is the picture of spiral model.

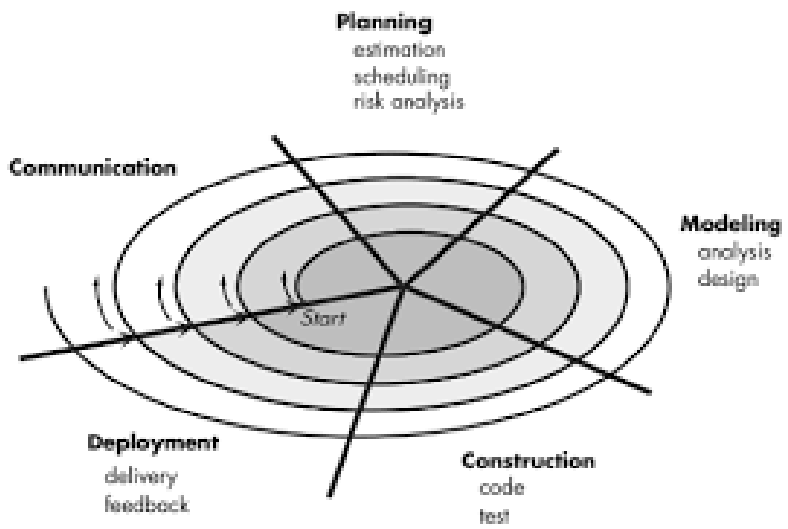

Figure 1. Spiral Model ${ }^{[7]}$

Above picture can be explained as follow:1) The first step starts with Communication is about building communication to users. Users in this case is the developer and users or students who will use the program later 2). The second step is planning is about we plan the activities that influence the sources, idea, duration and other information needed to develop the software. In this step is about analyse of technical and managerial risk. 3) The next step is the achievement of modelling, to develop more than one representative from the application. In this step can be drawn as architecture or face to face model. 4) After the step of modelling is contracting step, this is the coding and testing process toward application already given to end-user. In this step there is coding and programing language and testing concept of systematic design. 5) The last step is development, this proses is crucial to get the feedback from user based on the evaluation as the result it becomes user friendly.

B. Application Draft

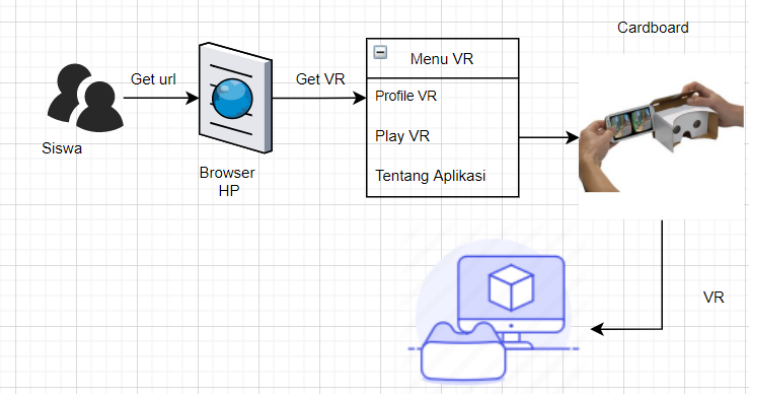

Figure 2. Application Draft

The explanation of the picture is as follows: first, students use a smartphone to open a browser application that is used to access the link provided by the school, after that a website image will appear which will automatically display virtual reality mode and then after the application opens and the VR mode appears, please use the cardboard to make the display look clearer and then please move your head upwards, to the right and to the left so the display of the application will follow our head movement. In the application, please select the "play VR" menu to observe objects by directing the circle point into the menu. While other menus available are the help menu, the application menu and the school profile menu. 
C. Analysis

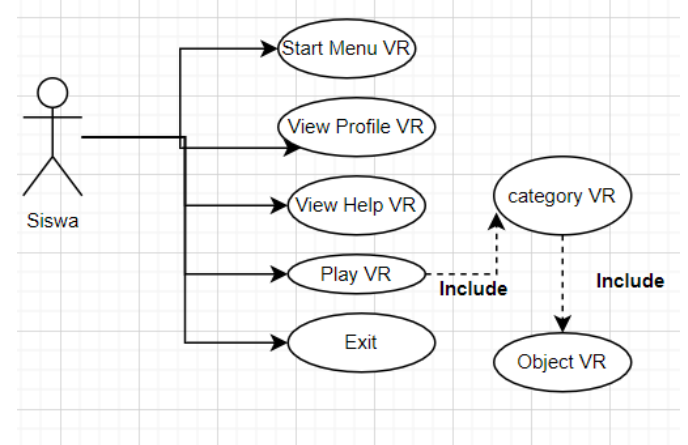

Figure 3. Use Case Diagram

In this stage of analysis, this system is analyzed using UML (unified modeling language) by displaying a use case diagram ${ }^{[9]}$ which shows the actor who uses the system and the functionality of the system. Meanwhile, the diagram class is used to show the system functionality to the user.

\section{RESULT AND DISCUSSION}

A. Main Menu

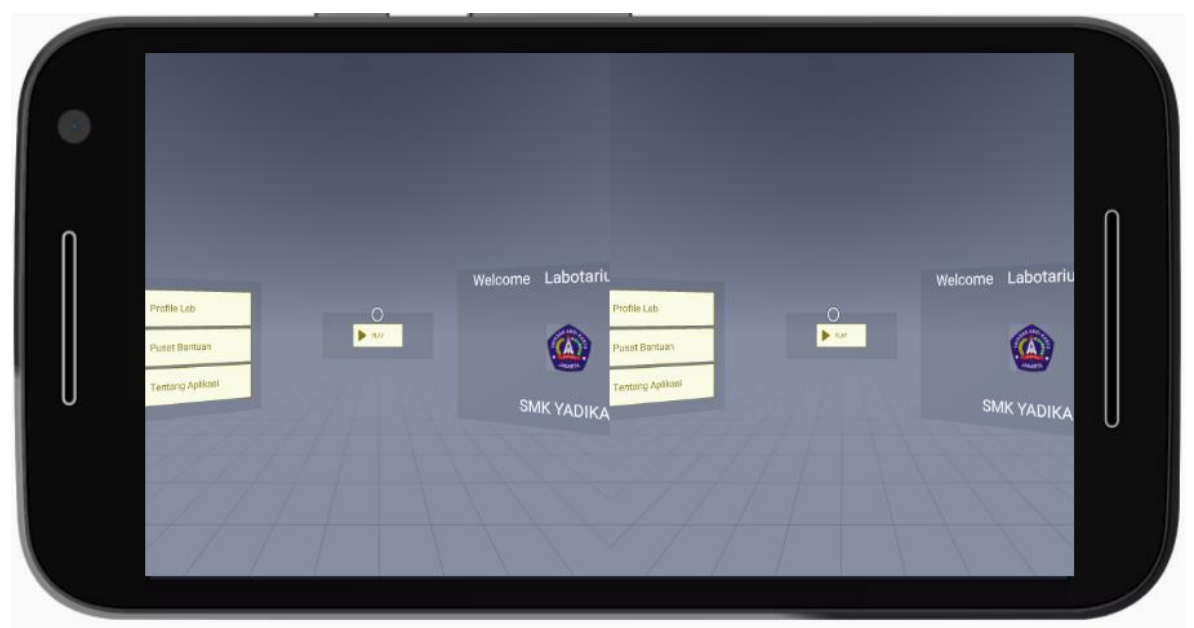

Figure 4. VR on Phone

The image above shows a part of VR that displays two images when using a phone. However, if you use a cardboard, the image will appear to be one. Here there is a menu that can be selected using the button. There are four buttons to choose. Namely: 1). VR Profile, 2). Help Center, 3) About App and 4) Play VR. and all can click just by moving your head and pressing a button. ${ }^{[8][9]}$ 
B. Profile

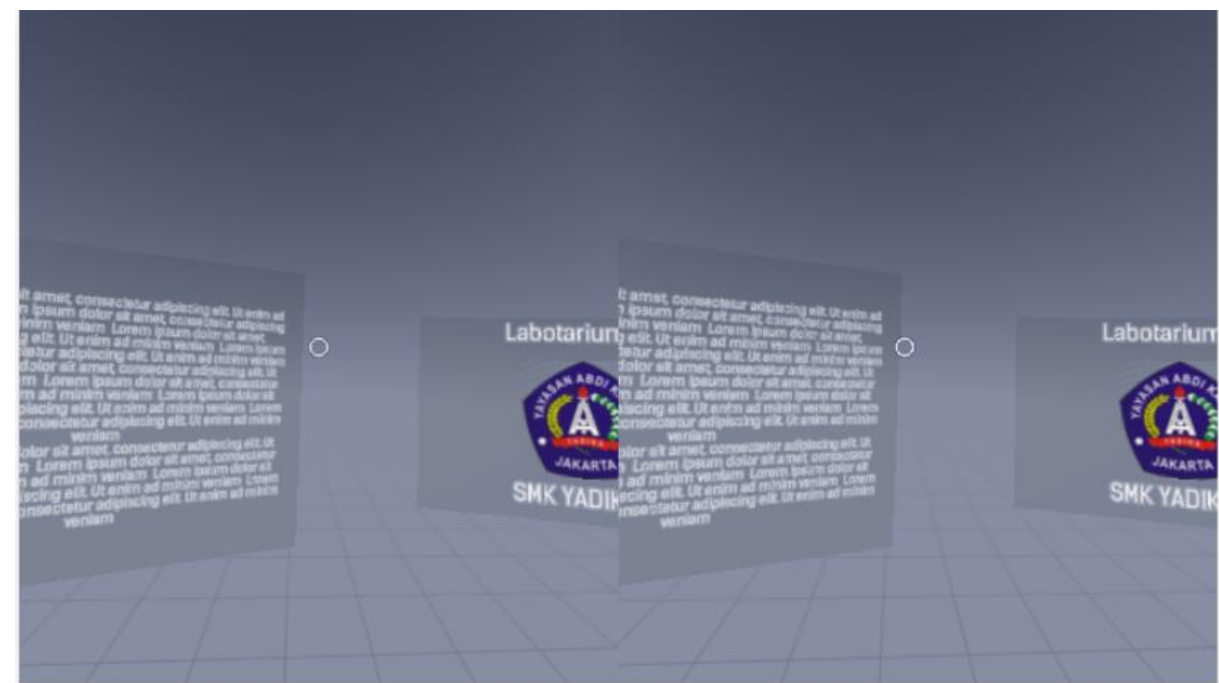

Figure 5. Profile Menu

In the Profile menu, students can see all school information in detail, while the school logo and button display can be changed according to the school's wishes. Changes can be made on the admin page. ${ }^{[8][9]}$

\section{Category}

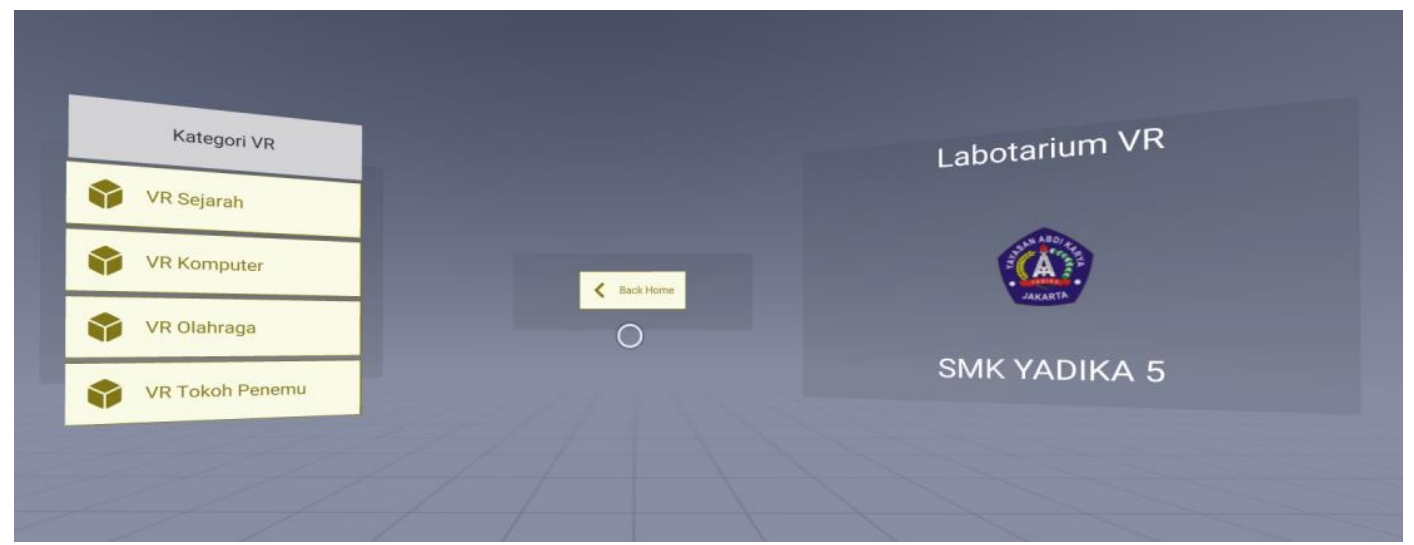

Figure 5. Category Menu

In this category menu students can choose the category according to the needs of the material taught by the teacher. All of these menus can be changed by the admin. To enter the category menu, simply connect the circle to the button, then it will automatically display the detail of category. ${ }^{[8][9]}$ 
D. Detail Category

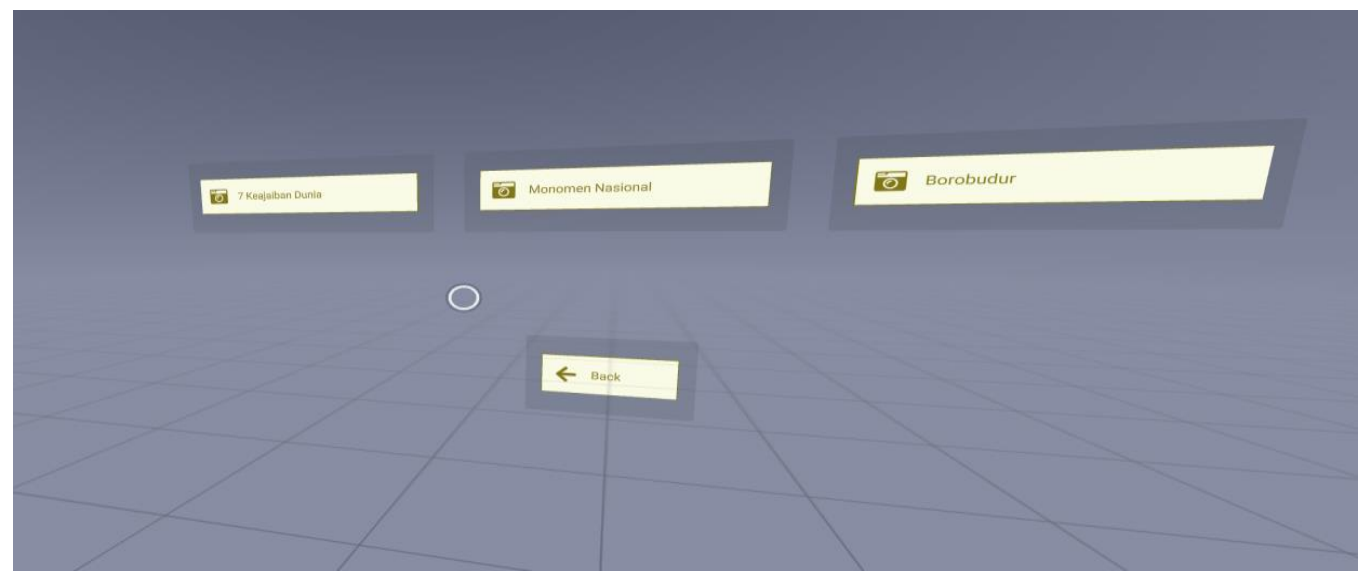

Figure 6. Detail Category Menu

In this section students can see every object that has been inputted by the administrator, as in the example above, props are made for objects in the seven wonders of the world. When students select the object, a 360 degree panoramic image is displayed which can be seen from all sides. To select it, simply connect the circle to the object's box. ${ }^{[8][9]}$

\section{E. VR Object}

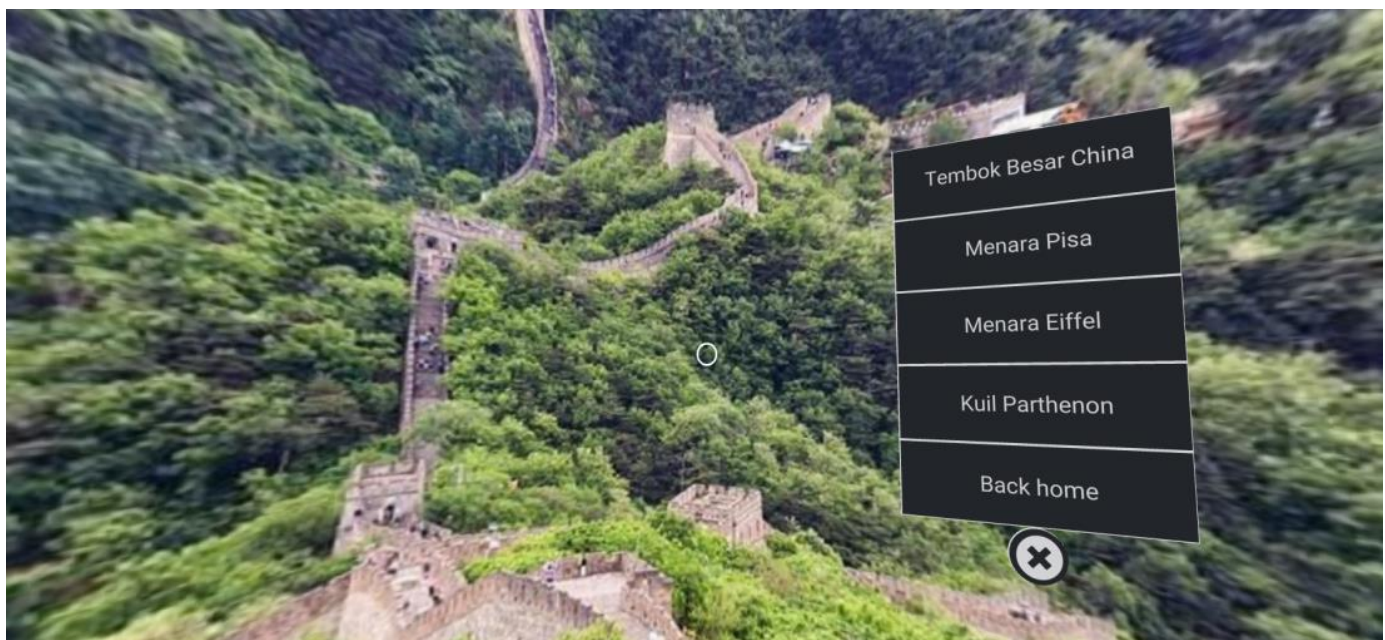

Figure 7. VR Object

At this stage students can analysis these objects as if they were in that place. This object can be rotated up to 360 degrees. This menu can also display several objects as shown in the picture. All of these objects can be changed by the admin on the admin menu. ${ }^{[8][9]}$ 
F. About Menu

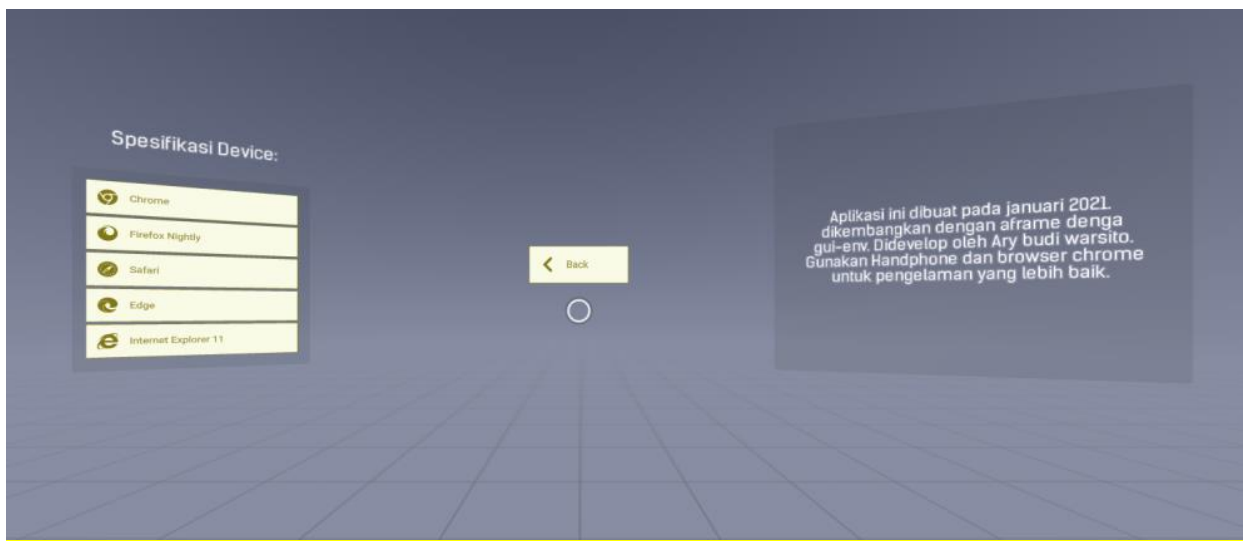

Figure 8. About Menu

This view is to inform who the user is in this project along with the version used and what specifications are needed to run this application. ${ }^{[8][9]}$

G. Login Page

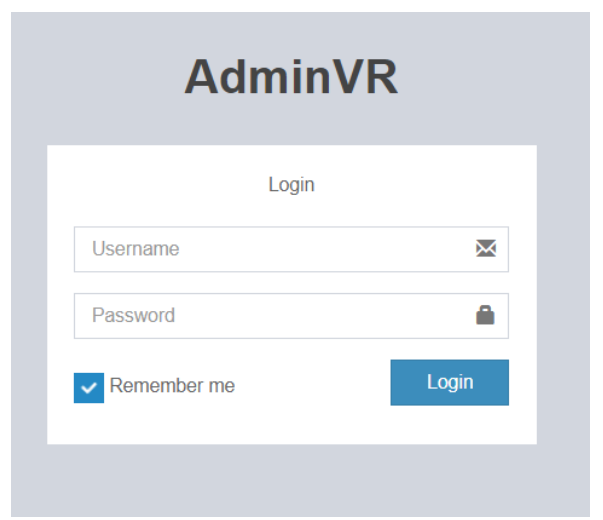

Figure 9. Login Page

Before entering into the system administrator. User Administrator must log in first. The image above is a VR login display where the user must enter a username and password in order to enter the dashboard page.

\section{H. Admin Menu}

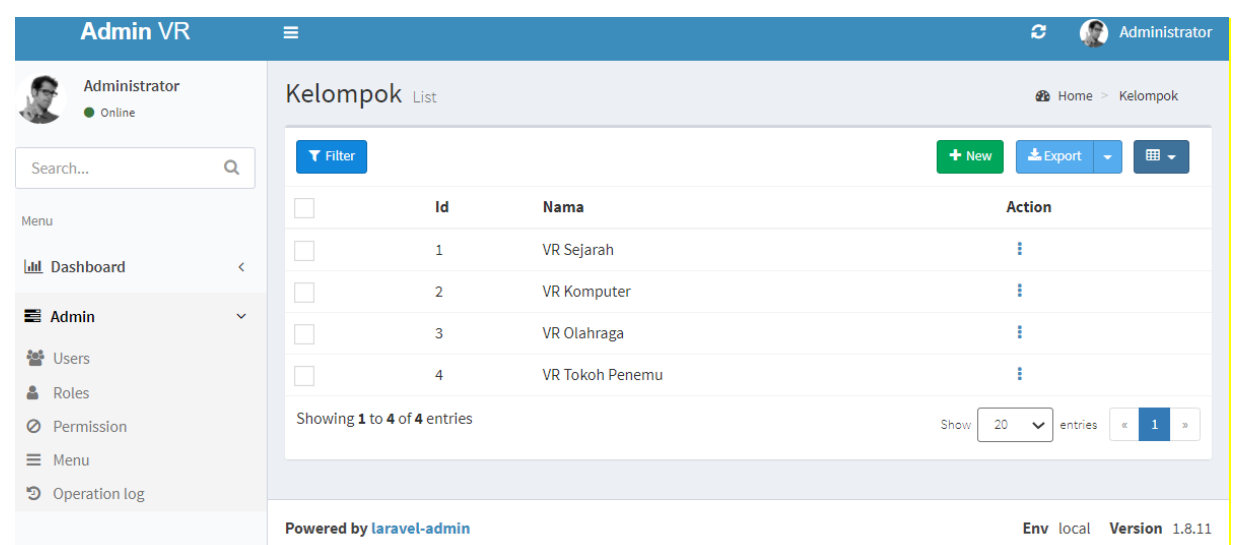

Figure 10. Input of Menu Category 
This is a view for the category menu of the administrator. In this Menu all VR objects can be created here.

\section{CONCLUSION}

This research concluded that this application can be used for study tours in the form of 360 degree panoramic photos, with this 360 degree view students can freely see objects without boundaries so that students can focus more on learning and feel more fun. This application is provided with two interfaces for frontend and backend. The frontend is used for students to see the visuals on virtual reality, while the backend is used for admins in managing virtual reality, such as entering images or put explanation about the picture for virtual reality.

\section{REFERENCES}

[1.] P. E. Berger, J. P. Matsuura, A. Barrios, P. Hopkins, M. T. Wagner, and M. Weston, Analyzing The Benefits Of Utilizing 360 Panoramic Photo Survey Technology On A Shell Offshore Platform. 2014.

[2.] Y. P. Edson, A. Wahyudi, and C. Dumingan, "A Proposed Combination of Photogrammetry, Augmented Reality and Virtual Reality Headset for heritage visualisation," in 2016 International Conference on Informatics and Computing (ICIC), Lombok, Indonesia, 2016, vol. 1, pp. 43-48.

[3.] A. Wahyudi, P. Adam, and G. Jesyriviano, "Virtual Reality of Historical Places in North Sulawesi," CogITo Smart J., vol. 3, no. 1, pp. 32-41, Jul. 2017.

[4.] R. A. Sahulata, A. Wahyudi, B. G. Wuwungan, and M. A. Nayoan, "Aplikasi Virtual Reality Pengenalan Kerangka Tubuh Manusia Berbasis Android," CogITo Smart J., vol. 2, no. 2, pp. 204-215, Dec. 2016.

[5.] A. Osman, N. Abdul Wahab, and M. H. Ismail, Development and Evaluation of an Interactive 360 Virtual Tour for Tourist Destinations, vol. 9. 2009.

[6.] X. Liu, Q. Xiao, V. Gopalakrishnan, B. Han, F. Qian, and M. Varvello, $360^{\circ}$ Innovations for Panoramic Video Streaming. 2017.

[7.] R. S. Pressman, Rekayasa perangkat lunak : pendekatan praktisi. Yogyakarta : Andi, 2002.

[8.] https://derryberni.medium.com/mengupas-a-frame-web-framework-virtual-reality662441f031f9\#: :text=A\%2Dframe\%20adalah\%20web\%20framework,sendiri\%20men ggunakan\%20kerangka\%20tree.js. diakses pada 12 Desember 2020

[9.] https://rdub80.github.io/aframe-gui/ diakses pada 12 Desember 2020 